\title{
EL EJÉRCITO LIBERTADOR CUBANO: NI TAN POBRES, NI TAN OLVIDADOS. SU LICENCIAMIENTO Y PAGO DE HABERES ENTRE 1899 Y
}

1903

\author{
ELIZABETH LÓPEZ MIR \\ UNIVERSIDAD DE LAS ARTES (ISA), CUBA
}

RESUMEN: En 1898 el Ejército Libertador Cubano fue licenciado y en 1903 obtuvo sus haberes de guerra. A través de una consulta de fondos documentales se pretende demostrar que esos pagos conllevaron a que los veteranos cubanos no estuvieran tan desatendidos por el gobierno republicano, ni mucho menos vivieran en la pobreza. Este último pago, fundamentalmente, permitió que los oficiales cubanos invirtieran en la política, en la economía y ocuparan un escaño en la sociedad de la entonces proclamada República de 1902. PALABRAS CLAVES: Ejército Libertador Cubano, licenciamiento, pago de haberes, veteranos, oficiales.

\section{THE LIBERATING ARMY CUBAN: NEITHER SO POOR, NEITHER SO FORGOTTEN. HIS DISMISSAL AND PAYMENT OF ASSETS BETWEEN 1899 AND 1903}

\begin{abstract}
In 1898 the Liberating Army the Cuban was licensed and you got his assets from war in 1903. It is intended to demonstrate through a consultation of documentary funds that those payments bore to that the veteran Cubans not be so disregarded for the republican Government, by no means live in poverty. This balloon payment, fundamentally, permitted that the official Cubans invest in the policy, in economy and occupy a seat in the society of the then proclaimed Republic of 1902.
\end{abstract}

KEYWORDS: Liberating Army Cuban, dismissal, payment of assets, veterans, officers. 


\section{A modo de introducción}

Con la firma del Tratado de París en agosto de 1898 se daba fin a la guerra Hispanonorteamericana y se pondría fin a la dominación colonial en Cuba. Para España el llamado “desastre del 98" condujo a la pérdida de sus últimas posesiones en América, especialmente de Cuba y Puerto Rico, generando así una fuerte crisis política, identitaria y cultural que generaría un fuerte pesimismo en la sociedad española.

A pesar de no haberse logrado la ansiada independencia en Cuba, el descontento de la sociedad civil cubana era notable. Se esperaba de inmediato la formación de un gobierno autónomo a la vez, que se ansiaba que un elemento tan simbólico como la bandera cubana ondeara en el Morro de la Habana. Sin embargo, tales esperanzas no se concretaron porque Estados Unidos en calidad de salvador impondría cuatro años de intervención militar en el país, y la bandera que se izó fue la estadounidense.

"El próximo advenimiento del siglo XX se identificó entonces con la instauración de una nueva era, marcada por dos aspiraciones en constante tensión: la modernización de las estructuras de la antigua colonia, frecuentemente traducida en términos de americanización institucional y cultural de la sociedad cubana, y el anhelo nacionalista de una república soberana e independiente." 1

En consecuencia, los principales órganos creados para la gestión de la independencia cubana serían disueltos, o sea, el Consejo de Gobierno de la República en Armas, el Partido Revolucionario Cubano y el Ejército Libertador. El primero, y en cumplimiento a lo establecido por la Constitución de La Yaya, entregó sus poderes a la Asamblea de Representantes del Ejército Libertador, y en constantes contradicciones entre Máximo Gómez y la nueva administración interventora, se disolvió el 4 de abril de 1899. El segundo fue disuelto por Tomás Estrada Palma desde el 21 de diciembre de 1898, quien había quedado al frente del mismo tras la muerte de José Martí.

Para el Ejército Libertador la situación fue más compleja porque además de implicar su desarme militar también exigía un pago a sus combatientes. El propio Ejército cubano creyó que serían reorganizados y pasarían a formar las filas del Ejército de la República, hecho que tampoco fue así. El hecho fue que el licenciamiento de las tropas cubanas se hizo en 1899, y para mantener a los oficiales tranquilos se les otorgó setenta y cinco pesos con la promesa de que en poco tiempo les serían liquidados sus haberes, acción que se concretó

${ }_{1}$ MARIAL, Iglesias: Las metáforas del cambio en la vida cotidiana: Cuba 1898-1902, La Habana, Ediciones Unión, 2010, p. 23. 
una vez establecida la República y constituyó la prioridad del gobierno cubano. La atención del Ejército Libertador era una cuestión primordial para los nuevos gobernantes cubanos, entre otras existen dos causas muy puntuales; una es la credibilidad hacia la nueva administración nacional que había dado su palabra en 1899, y otra era la necesidad de evitar una nueva reorganización e insurrección armada por parte de los oficiales cubanos al sentirse desatendidos. Es por ello que el gobierno cubano prefirió iniciar una República endeudada con treinta y cinco millones de pesos de oro americano, y de esta forma abonar a las fuerzas cubanas sus haberes en el transcurso del año 1903.

La mala interpretación de estos hechos y el desconocimiento han generado que muchos crean que el Ejército Libertador nunca llegó a recibir sus tan ansiados haberes de guerra. Por ello, se hace necesario ahondar a fondo en esta temática constituyendo ese el objetivo central de esta investigación: demostrar que el pago recibido por las tropas cubanas como haberes va más allá del mero licenciamiento.

A través de un minucioso trabajo con fuentes documentales procedentes en su mayoría del Archivo Nacional de Cuba, fundamentalmente del Fondo Donativos y Remisiones, a través de la recopilación de información se pudo constatar todos los trámites realizados por el gobierno republicano para la gestión por la paga desde fuera de la isla y la decisión de que de ser necesario se iría a Europa a pactarlo con alguna casa bancaria que le interesara. En los Estados Unidos los representantes cubanos enviados (Domingo Méndez Capote, Manuel Despaigne, Mario García Menocal y Ricardo Dolz) negociaron con casas como la Stillman (a través de James Stillman, presidente del The Nacional City Bank de New York), con la Schiff (con Jacob H. Schiff, gerente de la firma Kubm, Loeb \& Co.) y con la Speyer (con la casa Speyer \& Co. directamente). Finalmente, no fue necesario ir a Europa porque días después la Speyer \& Co cerraría el trato.

Asimismo, se consultaron diferentes bibliografías que nos ayudarían a constatar que los pagos a los que se referían en esos textos eran los recibidos como haberes por el Ejército cubano. Uno de estos casos serían las obras publicadas por Jorge Ibarra Cuesta ${ }^{2}$, Armando $\mathrm{Cuba}^{3}$, y Rolando Rodríguez ${ }^{4}$ qué nos revelan las circunstancias políticas y sociales en torno

\footnotetext{
2 IBARRA CUESTA, Jorge: Cuba: 1899-1920. Partidos políticos y clases sociales, La Habana, Editorial de Ciencias Sociales, 1992. IBARRA CUESTA, Jorge: Patria, etnia y nación, La Habana, Editorial de Ciencias Sociales, 2007.

${ }^{3}$ CUBA DE LA CRUZ, Armando: Holguín 1899-1920: de la Colonia a la República, Holguín, Ediciones Holguín, 2006.

4 "La disolución de Ejército Libertador. El gran objetivo de los Estados Unidos", Temas, No. 12-13, 1998, pp. 43-65.
} 
al licenciamiento del Ejercito Libertador cubano. Asimismo, es necesario mencionar que salvo los trabajos de Ibarra Cuesta antes mencionados, se carece de obras que hayan tratado el tema referente al pago de los haberes de guerra al Ejército cubano, salvo algunos que han abordado temáticas relacionadas con el propio organismo militar en el intento de demostrar la existencia de una burguesía dependiente en el país.

Para el desarrollo del presente trabajo tuvimos acceso a las listas de pago del Segundo Cuerpo del Ejército Libertador que operaba al Oriente del país y representaba el 21,76\% del total nacional. Ese desglose de pago ofrecido por las listas nos presenta en qué medida fueron repartidos esos haberes. Es por esto que afirmamos a lo largo de la investigación que no fue absolutamente distribuido por grado militar, sino también por la función política ejercida dentro de la guerra. En este caso podemos citar al Coronel Rafael Manduley del Río quien se licenció en 1899 con el grado de Coronel, pero cobró sus haberes como Mayor General pues había sido Jefe del Estado Mayor del Segundo Cuerpo, Delegado, y después Vicepresidente de la Asamblea de Jimaguayú, así como en 1896 Sub-Secretario de Guerra llegando a ser Secretario por sustitución.

Las circunstancias en que se realiza el licenciamiento y el pago de honorarios difieren no solo en tiempo, sino en contexto. El primero se ejecutó como medida por parte del gobierno interventor de desarticular todo el aparato gubernamental colonial y bajo la premisa de una necesaria reorganización de la Isla; y el segundo cuando ya estaba instaurado un gobierno republicano al que se le tornó una necesidad atender a las tropas cubanas que cuatro años después de su desarme se mostraban inconformes con su tratamiento.

¿Por qué recobra tanta importancia que el Ejército Libertador recibiera o no su pago de guerra? Por la propia razón de que ese dinero le permitiría invertir y formar parte de la burguesía de Cuba durante los primeros años del siglo XX. Este proceso de enriquecimiento personal también tuvo un trasfondo político posibilitando la incursión de los caudillos de guerra en la esfera política. El caciquismo político cubano saldría a la escena nacional en el momento en que los antiguos combatientes del ejército cubano se enriquecen. No obstante, el problema del pago va más allá de un movimiento económico, constituyendo un fenómeno social y político que condiciona el devenir de la República cubana en sus primeros veinte años. 


\section{El licenciamiento del Ejército Libertador Cubano. Sus principales premisas}

$\mathrm{Al}$ acontecer la firma del Tratado de Paris en 1898, España pierde sus últimas colonias en América, en particular Cuba. A partir de entonces el gobierno militar de Leonard Wood emprendería un proceso de desarticulación de las principales instituciones creadas por las fuerzas revolucionarias durante la guerra. Una de ellas sería el Ejército Libertador Cubano. La premisa para su licenciamiento fue justificado con el argumento de que su desarme era "la mejor muestra de la pacificación de la Isla, exigencia básica de la Resolución Conjunta".

Desmovilizar al ejército cubano constituyó un proceso muy complejo, con más de 69 718 hombres incluyendo al Cuerpo Auxiliar Civil. ${ }^{6}$ No obstante, la complejidad mayor recaía en el pago por sus servicios, imposible de solucionar para Cuba que, bajo una intervención de cuatro años por parte de los Estados Unidos, debía reparar su economía, restaurar sus ciudades devastadas por la guerra y cambiar la mentalidad de sus habitantes marcada por los vestigios coloniales.

Sin embargo, este proceso de licenciamiento del Ejército Libertador Cubano fue ejecutado en dos momentos distintos, el primero se caracterizó por la desmovilización de las tropas, y el segundo estuvo relacionado con el pago de los haberes de guerra. En la historiografía se ha tendido a confundir ambos momentos como uno solo por lo cual se tratarán de explicar a continuación.

El licenciamiento del Ejercito Libertador ocurrió en la medida que se desarticulaba a la propia institución armada bajo las Reglas para el Licenciamiento del Ejército Libertador y publicado en Gaceta Oficial el 10 de mayo de $1899,{ }^{7}$ en el artículo II se planteaba

"Se entregará a cada individuo (clase o soldado) del Ejército Cubano, que hubiese estado en servicio en julio 17, 1898, o con anterioridad a esta fecha, y que se presente con sus armas y equipos, la cantidad de setenta y cinco pesos (\$75.00), moneda de los Estados Unidos, siempre que no se hallare, en la actualidad, desempeñando destino alguno público (civil o militar), ni en el concepto de subalterno, policía (rural o municipal) o cualquier otro destino del Gobierno por el que reciba un sueldo fijo.” 8

\footnotetext{
${ }^{5}$ RODRÍGUEZ, Rolando: op. cit, p. 43.

${ }^{6}$ Un listado de todos los oficiales del Ejército Libertador Cubano por grado se puede encontrar en ROLOFF, Carlos: Índice alfabético y defunciones del Ejército Libertador de Cuba, La Habana, Rambla y Bouza, 1901.

${ }^{7}$ La Gaceta Oficial de la República de Cuba fue una publicación de circulación trimestral fundada en 1790 y constituyó un órgano oficial de publicidad normativa. Tiene sus orígenes en la Gaceta de Madrid dada la condición de provincia de ultramar que tenía la Isla. En 1899, fue dictada la Orden Militar No. 31 que la reconocía como Gaceta Oficial del Gobierno Militar de La Habana. A partir de 1902 se rigió por el Decreto No. 8 del 20 de mayo de 1902 que la declara como periódico Oficial del Gobierno.

8 PICHARDO, Hortensia: Documentos para la historia de Cuba, La Habana, Editorial Ciencias Sociales, 1973, T.II p. 30.
} 
Para el pago de esos setenta y cinco pesos se estipuló un convenio entre el Gobernador General y el General Máximo Gómez de destinar 3 millones de pesos en moneda de los Estados Unidos. Por tanto, según lo estipulado en las Reglas se pagaron un total de $\$ 2554750.00^{9}$ de los tres millones. Las Reglas también agregaban que a cada hombre le serían recogidos su equipamiento y las armas. En el artículo IX establecía que el armamento se trasladaría a La Habana o a Santiago de Cuba y se conservarían como recuerdos estando al cuidado de armeros nombrados por el General en jefe del Ejército cubano.

De esta manera el Ejército cubano quedaba liberado de cualquier función y cada uno de sus miembros pasaron a ser personal civil de la República que nació en 1902 con el presagio de una deuda, la cual tenía como fin pagar al Ejército Libertador sus haberes de guerra.

\section{El pago al Ejército Libertador Cubano: sus haberes de guerra. Una inversión a gran escala}

El primer presidente cubano Tomás Estada Palma, quien tras la muerte de José Martí ocuparía el cargo como delegado del Partido Revolucionario Cubano, pactaría con la casa bancaria estadounidense Speyer \& Co un empréstito de 35 millones de pesos en oro americano comprometiendo como pago el $10 \%$ del ingreso a la aduana cubana por un período de diez años. El documento disponía en sus artículos:

"Art.3 - tanto el capital como el interés de este empréstito serán pagados en oro y serán libres para siempre de todo impuesto cubano existente o futuro de cualquier naturaleza que sea.

Art.4 - como garantía especial del exacto cumplimiento del pago de dicho interés se asigna [...] el $15 \%$ del total del monto de los derechos rentas o entradas que perciben las Aduanas de la República sean cuales fueran la denominación especial de esos derechos $[\ldots]$ los derechos de las Aduanas así consignados deberán exceder cada año fiscal en $10 \%$ de la cantidad requerida para el pago de interés y amortización.”10

La gestión por el pago se concertó según una comunicación enviada al Ministro de Cuba en Washington, Gonzalo de Quesada, por parte de la Casa Speyer \& Co. donde manifestaba: "estamos dispuestos a enviar a nuestro representante a La Habana, lo más pronto posible, para negociar con el presidente Palma el empréstito de los 35 millones". 8

\footnotetext{
9 IBARRA CUESTA, Jorge: Cuba: 1899-1920. Partidos políticos y clases sociales. Op. cit., p.194.

${ }^{10}$ ARCHIVO NACIONAL DE CUBA (ANC): Fondo Donativos y Remisiones, leg. 373, exp. 25.
} 
Todo quedó registrado en la Ley del empréstito de los 35 millones, fechado el 27 de febrero de 1903 y modificada el 13 de junio del mismo año. Así, la acción que se materializó en 1903 comenzaría desde 1899 con una normativa fechada el 12 de enero de 1899 dirigida a los Jefes de Cuerpo, División, Brigada y Regimiento por el Mayor General Carlos Roloff, Inspector General del Ejército Libertador Cubano, publicada más tarde en su índice alfabético y de defunciones del Ejército Libertador.

\section{Imagen 1}

Circular emitida a Jefes del Ejército Libertador para formalizar inscripción por la paga de haberes, 1899

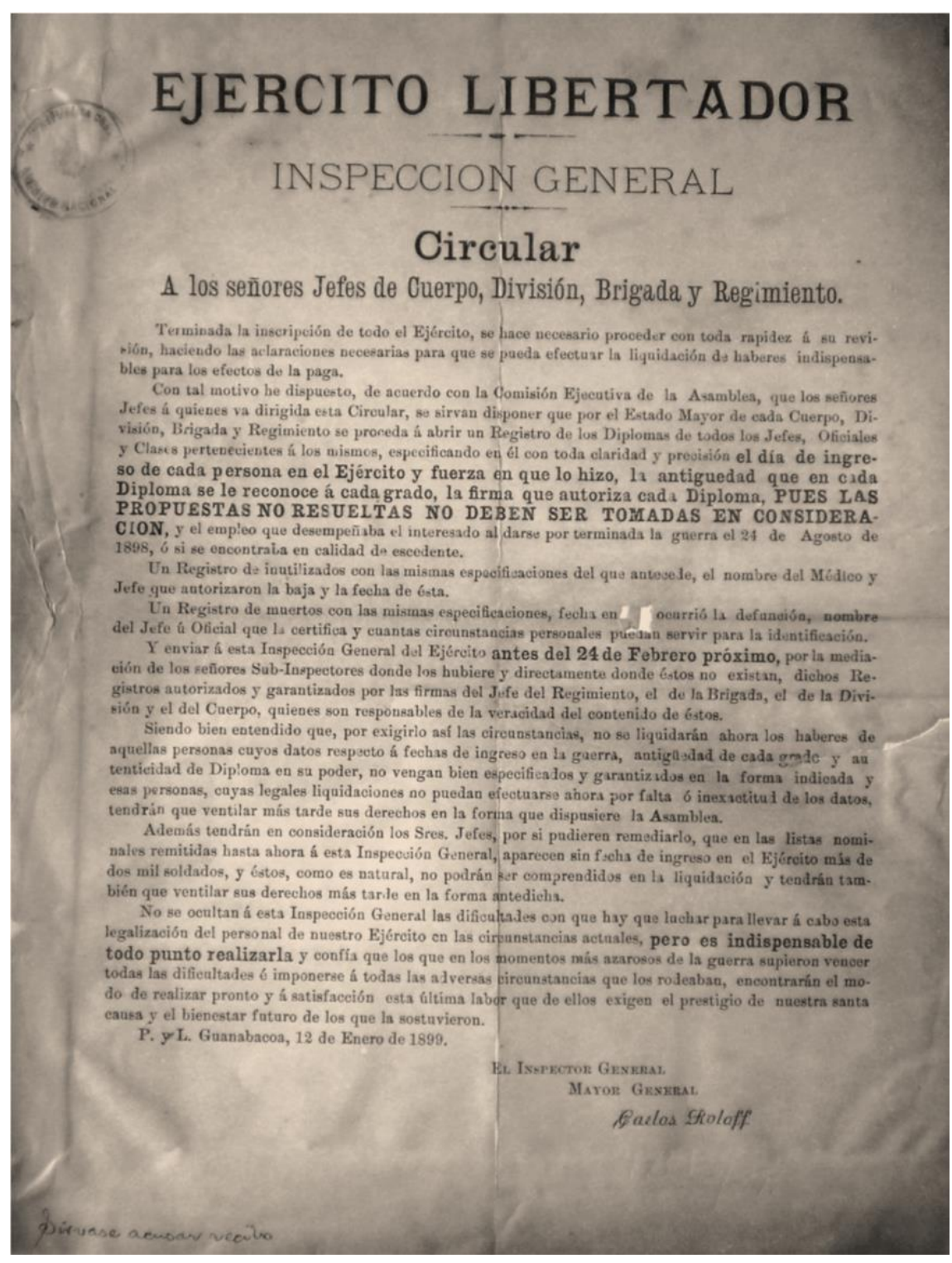

Fuente: Archivo Nacional de Cuba, Fondo Gobierno de la revolución del 95, leg 63, exp. 8892, 12-1-1899 
Dicha circular aportaba todas las órdenes precisas para lograr una organización del proceso en el momento de efectuarse. Entre sus exigencias contemplaba:

“[...] se procederá a abrir un Registro de Diplomas de todos los Jefes, oficiales y clases $[. .$.$] especificando en él el día de ingreso de cada persona al Ejército y fuerza en que$ lo hizo, la antigüedad que en cada diploma se le reconoce a cada grado, la firma que autoriza cada diploma y el empleo que desempeñaba el interesado al darse por terminada la guerra el 24 de agosto de 1898, o si se encontraba en calidad de ascendente." ${ }^{11}$

La labor iniciada por Roloff quedó materializada cuando el periódico Herald de New York, fechado el 3 de febrero de 1899, informó que el Presidente de los Estados Unidos había recibido de la Asamblea de Representantes de Cuba la constitución de las fuerzas del Ejército Libertador, el cual estaba compuesto por 44932 hombres distribuidos de la siguiente forma:

"11 Mayores Generales, 19 Generales de División, 54 Generales de Brigada, 163 Coroneles, 290 Tenientes Coroneles, 578 Comandantes, 965 Capitanes, 1245 Tenientes, 1 794 Subtenientes, 2130 Sargentos Mayores, 3123 Sargentos Segundos, 4500 Cabos y 30060 Soldados." 12

Esta relación no contemplaba al Cuerpo Auxiliar Civil, cuyos integrantes habían trabajado en las prefecturas y/o colaborado desde el extranjero.

Al proclamarse la República de Cuba, el 20 de mayo de 1902, los nuevos dirigentes crearían una comisión revisadora y liquidadora de los haberes del Ejército Libertador el 16 de agosto de 1902, presidida por el general Máximo Gómez y fungiendo como vocales los Generales José Miró Argenter y Javier de la Vega. Dos días después, en Santiago de Cuba, circularía la información sobre el inicio de los trámites para el pago al Ejército Libertador donde se planteaba la necesidad de, "gestionar que las cámaras legislativas promulguen una legislación por la que queden reconocidos los grados militares que adquirieron en la lucha por la independencia". ${ }^{13}$

La relación ofrecida por Carlos Roloff declararía un total de 69718 miembros. Por su parte, la nombrada comisión publicaría un resumen, con fecha 23 de julio de 1903, donde ofreció la relación de los veteranos y su correspondiente pago por grado militar obtenido en servicio. Desglosaba esta vez las fuerzas cubanas del siguiente modo:

\footnotetext{
11 ANC: Fondo Gobierno de la Revolución del 95, leg 63, exp. 8892, 12-1-1899.

12 ARCHIVO MUSEO PROVINCIAL DE HISTORIA DE HOLGUIN (AMPHH): Fondo José A. García Castañeda, doc. 155.

${ }^{13}$ ANC: Fondo Donativos y Remisiones, Legajo 159, doc. 33.
} 
"22 Mayores Generales, 23 Generales de División, 68 Generales de Brigada, 205 Coroneles, 395 Tenientes Coroneles, 724 Comandantes, 1116 Capitanes, 1136 Tenientes, 1 847 Subtenientes o Alférez, 1784 Sargentos Mayores, 2294 Sargentos Segundos, 2468 Cabos y 41492 Soldados." 14

Contabilizando unos 53574 oficiales. La diferencia entre las listas de pago emitidas por la Comisión y el Índice de miembros del Ejército cubano ofrecido por Roloff podría radicar en varios aspectos, teniendo en cuenta la orden emitida en 1899, antes mencionada. Se agrega en ella que:

“[...] no se liquidarán los haberes de aquellas personas cuyos datos respecto a fechas de ingreso en la guerra, antigüedad de cada grado y autenticidad de Diploma en su poder, no vengan bien especificados y garantizados en la forma indicada [...] Además, en las listas nominales remitidas hasta ahora a esta Inspección General, aparecen sin fecha de ingreso al Ejército más de dos mil soldados, y estos, como es natural, no podrán ser comprendidos en la liquidación." 15

Entonces, se puede atribuir a criterios como la no aceptación por falta de pruebas al momento de inscripción, ausencia de la fecha de ingreso al Ejército o por fallecimiento desde 1899, cuando Roloff elabora su relación de oficiales, hasta 1903 año en que ocurre la revisión efectuada por la Comisión. En el mismo 1903, salieron publicadas en todo el país las relaciones de pago a los seis cuerpos de veteranos del Ejército Libertador. A partir del año 1904, se distribuyeron para el pago unos \$31 589044 monedas de oro de los Estados Unidos.

Tabla 1

Liquidación de haberes al Ejército Libertador Cubano

\begin{tabular}{|l|c|c|c|}
\hline Graduación & Hombres & $\begin{array}{c}\text { Sueldo (\$ oro en } \\
\text { EEUU) }\end{array}$ & Promedio \\
\hline Mayores Generales & 22 & 264383 & 12017 \\
\hline Generales de División & 23 & 137601 & 5956 \\
\hline Generales de Brigada & 68 & 490006 & 7205 \\
\hline Coroneles & 205 & 1134650 & 5534 \\
\hline Tenientes Coroneles & 395 & 1880652 & 4837 \\
\hline Continúa en la siguiente página... & & & \\
\hline
\end{tabular}

${ }^{14}$ IBARRA CUESTA, Jorge: Patria, etnia y nación, op. cit., p. 172.

15 ANC: Fondo Gobierno de la Revolución del 95, Leg. 63, Exp. 8892 


\begin{tabular}{|l|c|c|c|}
\hline Comandantes & 724 & 3226565 & 4456 \\
\hline Capitanes & 1116 & 3044447 & 2738 \\
\hline Tenientes & 1136 & 2863010 & 2529 \\
\hline Alféreces & 1847 & 3571856 & 1933 \\
\hline Total jefes y oficiales & 5536 & 15913856 & \\
\hline Sargentos 1ra & 1784 & 1895721 & 1063 \\
\hline Sargentos 2da & 2294 & 1914407 & 834 \\
\hline Cabos & 2468 & 1552381 & 628 \\
\hline Soldados & 41492 & 9613365 & 231 \\
\hline Total clases y soldados & 59104 & 47472900 & 39151 \\
\hline
\end{tabular}

Fuente: IBARRA CUESTA, Jorge: Cuba 1898-1921 ...

Si analizamos el pago en un escenario regional y no nacional vamos a apreciar el promedio recibido con más exactitud. Por ejemplo, al Segundo Cuerpo del Ejército Libertador que tenía su zona de operaciones entre el Valle del Cauto y el Norte del Oriente cubano, le correspondió a sus miembros una cantidad que oscilaba entre los casi 18000 para los Generales y otros 1800 para los alférez o subtenientes.

\section{Tabla 2}

Liquidación de los haberes al Segundo Cuerpo del Ejército Libertador

\begin{tabular}{|l|c|c|c|}
\hline Grado & $\begin{array}{c}\text { Total de } \\
\text { oficiales }\end{array}$ & $\begin{array}{c}\text { Total de } \\
\text { haberes (\$) }\end{array}$ & $\begin{array}{c}\text { Promedio } \\
\text { recibido (\$) }\end{array}$ \\
\hline Mayores Generales & 4 & 71766.64 & 17941,66 \\
\hline General de División & 4 & 62761.47 & 15690.36 \\
\hline General de Brigada & 12 & 125469.57 & 10455.79 \\
\hline Coronel & 35 & 294569.25 & 816.26 \\
\hline Teniente Coronel & 76 & 609073.65 & 698.33 \\
\hline Comandante & 128 & 647265.45 & 3067.60 \\
\hline Capitán & 211 & 537864.18 & 2359.05 \\
\hline Teniente & 228 & & \\
\hline Continúa en la siguiente página... & & & \\
\hline
\end{tabular}




\begin{tabular}{|l|c|c|c|}
\hline Alférez (Subteniente) & 325 & 600206.33 & 1846.78 \\
\hline Total de Altos Jefes y oficiales & 1023 & 3455308.99 & 3377,62 \\
\hline Total de Clases y Soldados & 10637 & 11734997,46 & 1103,22 \\
\hline Total & 11660 & 15190306.45 & 1302,77 \\
\hline
\end{tabular}

Fuente: Datos extraídos de LÓPEZ MIR, Elizabeth: El caciquismo político en la región histórica de Holguin (1899-1920), Tesis de Maestría, La Habana, Instituto de Historia de Cuba, 2016.

De esta forma, el pago se convirtió en un símbolo de bienestar para los miembros del antiguo Ejército Libertador. No obstante, se transformó en una vía de enriquecimiento por las inversiones económicas que generaría, y de este modo crecerían los sectores de la economía, a la vez que constituiría un interés para los sectores privados ante la posibilidad de un aumento de la demanda ante la oferta. En otro orden, no menos importante, fue muy beneficioso para los oficiales debido a la posibilidad de convertirse en nuevos propietarios e insertarse en la sociedad cubana emergente.

Los veteranos, convertidos con la guerra en hombres valerosos y admirados, poseían una cuota de prestigio y carisma ante la sociedad. No importa su procedencia social ni su instrucción previa a la guerra, el pago los situó en un estatus social diferente al que antes tenían. Un ejemplo de ellos fue el Teniente Coronel Francisco Franco Ortiz, de Banes, quien era negro y analfabeto, pero pudo comprar haciendas y ejercer dentro del comercio en la zona, convirtiéndose de esta forma en un hombre acaudalado gracias a los $\$ 7$ 970,66 que recibió.

Para el gobierno de la República representaba una obligación -y a la vez un beneficioefectuar dicho pago porque estos hombres tenían ganada la simpatía de todo el pueblo, y cuanto más rápido se atendieran sus necesidades, más pronto el pueblo creería en la nueva administración nacional.

De esta manera lo entendían todos. En una reunión de oficiales presidida por el general Vicente Miniet, la cual tuvo como objetivo solicitarle al Gobierno de la República el pago de los haberes de los soldados de la Revolución por los medios más breves y equitativos, el argumento era que: "al hacer efectiva la paga al Ejército se aplacaba el malestar que se siente en las clases menesterosas y tomarían incremento la agricultura y las industrias del país". ${ }^{16}$ De este modo confirmaban que el movimiento por la paga era "general en toda la isla por los Veteranos." 17

16 ANC: Fondo Donativos y Remisiones, Legajo 159, Doc. 33.

${ }^{17}$ Ibídem. 
La prensa lo interpretó de la misma manera. El Diario de la Marina, se refirió a que el empréstito sería apoyado por todas las clases del país:

"servirá para dar entrada en Cuba a un dinero que en su mayor parte será destinado al fomento y desarrollo de la riqueza pública. Por otra parte, el presidente le prestará la atención debida para evitar la muerte de las industrias, la ruina del comercio y hacer posible la paga al Ejército."18

Por su parte, en el The Sun, de New York, con fecha 30 de octubre de 1903 se publicaría un artículo titulado, El empréstito cubano y la Enmienda Platt, donde se analizarían las cláusulas estipuladas en el apéndice constitucional, y la concertación del empréstito violaría tal estatuto, pues hasta la fecha no se tenía concretada la acción con ningún prestamista. Así, el gobierno había resuelto dar como garantía los productos de las Aduanas:

“[...] el artículo 11 de la Enmienda Platt declara que Cuba no podrá contraer deuda pública alguna, que no pueda pagarse con los ingresos ordinarios después de cubiertos los gastos corrientes del Gobierno [...] la recaudación de las Aduanas constituyen cerca del $95 \%$ de las entradas de la Isla y constituye la única base segura para el pago de los gastos corrientes." 17

El diario Correo de Oriente, en noviembre de 1903, sacaría a la luz el artículo El empréstito, buenas impresiones, en el que alentaba a los veteranos de la próxima llegada de su pago en retribución a sus luchas por la independencia del país:

"El empréstito se hará. La legión de bravos que abandonaron cuanto hace dulce su existencia para formar Patria, alcanzará en breve recursos con que reparar algo que es reportable a sus ofrendas a la amada Patria [...] las facilidades para la vida material [...]. Se les restará íntegra otra deuda: la de la gratitud; pero esta le será perfecta y profundamente acreditada en el sentimiento del pueblo cubano." 18

Hasta los ayuntamientos se planificaron ante la irrupción de capital que sobrevendría con tales pagos. El de Puerto Padre en la región de Las Tunas, por ejemplo, solicitaría un aumento en el presupuesto para el año fiscal 1904 - 1905 en concepto de Impuesto Industrial. Lo argumentaba de la siguiente manera:

"Atendiendo al incremento y vida floreciente y próspera del comercio en este Término y creyendo que este incremento será aún más efectivo, cuando, como es seguro, en el próximo año fiscal, se verifique el pago de los haberes del Ejército Libertador, se acuerda aumentar este concepto a la cifra de cinco mil ochocientos dieciséis pesos (5 816.00).”19

\footnotetext{
${ }^{18}$ Ibídem.

${ }^{19}$ ANC: Fondo: Secretaría de Gobernación, Legajo 38, Exp. 223.
} 


\section{Las pensiones de veteranos: otra remuneración por la guerra}

Pero la atención a los antiguos libertadores cubanos no se limitó a los dos momentos analizados anteriormente. El 11 de julio de 1918, el general y presidente de la República Mario García Menocal, aprobó la Ley de Pensiones para los miembros del Ejército Libertador y su Cuerpo Auxiliar Civil. Esta ley reconocía el derecho a una pensión anual y estaba dirigida a los miembros del Ejército cubano, a su Cuerpo Auxiliar Civil y también, en su ausencia, a sus familiares.

En el Artículo VI regulaba que las pensiones oscilaban, de acuerdo al grado militar, entre los 3600 pesos anuales para los Mayores Generales hasta los 360 para los soldados.

Tabla 2

Pensiones para los miembros del Ejército Libertador y su Cuerpo Auxiliar Civil

\begin{tabular}{|l|l|}
\hline Grado & Pensión \\
\hline Mayores Generales & 3600 \\
\hline Generales de División & 3300 \\
\hline Generales de Brigada & 3000 \\
\hline Coroneles & 2400 \\
\hline Tenientes Coroneles & 2000 \\
\hline Comandantes & 1600 \\
\hline Capitanes & 1200 \\
\hline Tenientes o Primeros Tenientes & 1000 \\
\hline Segundos Tenientes, Sub-Tenientes o Alférez & 840 \\
\hline Sargentos Primeros & 600 \\
\hline Sargentos Segundos o Sargentos & 540 \\
\hline Cabos & 480 \\
\hline Soldados & 360 \\
\hline
\end{tabular}

Fuente: Gaceta Oficial de la República de Cuba el día 11 de julio de 1918

También la ley tenía en cuenta a los oficiales que habían sido mutilados en alguna acción de guerra durante el servicio activo. Para estos otorgaba el $20 \%$ por encima de la cuantía fijada, siempre y cuando el valor no sobrepasara de los 1000 pesos. En el caso de corresponderle cobrar la pensión a un familiar, la cantidad recibida correspondería al 75\% de la reglamentada. 


\section{La consecuencia política: la emergencia del caciquismo}

El caciquismo político en Cuba emergió como una respuesta al proceso político que nació con la propia guerra por las características que tuvo: regional. Bien por intereses, ideologías o imperativos del proceso bélico, la guerra matizaría la estrategia de acción de los caudillos a lo largo y ancho de la geografía insular conllevando a la existencia de un líder insustituible en su territorio y representante de los intereses de los habitantes. Se consolidó con la propia República y tuvo su ensayo durante el período de ocupación estadounidense que le antecedió, al colocar a esos mismos líderes al frente de los Ayuntamientos siendo una estrategia de aceptación y credibilidad en la nueva gestión administrativa.

Sin embargo, el caudillo militar que pasó a ser cacique político, aunque bajo las mismas normas de liderazgo e intereses en su respectivo enclave regional, solidificó su gestión con el apoyo de una clientela permitiéndole su movilidad en los puestos públicos. Detrás de ese ascenso político estuvieron dos pautas claves, una fueron los factores externos díganse las empresas extrajeras, el amiguismo, el populismo, y segundo, el ya mencionado pago de haberes en la medida que les permitió utilizar ese dinero para el nuevo oficio: la política.

De un estudio de caso realizado anteriormente en el afán de demostrar la existencia del caciquismo en la región histórica de Holguín matizada por las inversiones de capital extranjero, especialmente el estadounidense, ${ }^{20}$ se pudo comprobar que en la zona los caciques políticos articularon sus negocios con las compañías extranjeras, en particular con la United Fruit Company y The Cuban American Sugar Company, enclavadas en Banes y Puerto Padre, respectivamente, pero con un radio de acción que traspasaban dichas comarcas. Estas compañías les propiciaron a los caciques los recursos financieros necesarios para consolidarse en sus respectivos enclaves económicos y en sus cargos políticos, con vistas a que representaran los intereses del capital foráneo.

Podemos mencionar casos como el de Mario García Menocal quien ostentó el grado de Mayor General y una vez instaurada la República en 1902 se dedicó a administrar en Central Chaparra en Puerto Padre. Menocal negociaba "favores" directamente con el gobierno local, por ejemplo, ofrece los postes para el alumbrado local o gestiona una ley en el senado en pos de constituirse una Aduana en ese puerto. No fue nada casual que cuando decidió postularse para la candidatura presidencial fueron los habitantes de ese pueblo sus más fieles votantes.

\footnotetext{
${ }^{20}$ Se estudiaron 33 individuos haciendo coincidir el escenario de operaciones del segundo cuerpo del Ejército Libertador con la región de operaciones, dígase Holguín, Puerto Padre y Banes, después de la guerra y que alternaron su profesión con su actividad económica o política. Con el pago de los haberes de guerra pudieron incursionar en la política o comprar tierras o ejercer ambas prácticas inclusive.
} 
Otro caso digno de mencionar en ese apartado fue el de Juan Vicente Cárdenas, quien había sido Teniente Coronel durante la guerra y ya en la independencia era el Jefe Comercial de la United Fruit Company en Banes. Vicente Cárdenas tramitó préstamos de parte de la empresa destinados a obras públicas como el alcantarillado para el área residencial de la ciudad, las calles, la carretera al Embarcadero, etc., siendo en 1910, fecha en la que se declara a Banes como Ayuntamiento, electo como su primer Alcalde.

Por ende, la mayor parte de los cargos electos en la región holguinera fueron ocupados por la antigua oficialidad del Ejército cubano. El acceso a la documentación de la oficialidad holguinera tras el proceso de licenciamiento del Ejército Libertador permitió analizar el proceso de emergencia y consolidación del libertador-terrateniente-cacique rural. La mayoría de los cargos electivos fueron ocupados por mayores generales y coroneles, los cuales, a su vez, en sus múltiples variantes se dedicaron por lo general a la explotación del colonato azucarero, vinculados a las empresas extranjeras.

Si tenemos en cuenta la cifra obtenida por cada oficial y el costo de la tierra en Cuba en esos años podemos calcular cuántas caballerías de tierra se podían adquirir. Por ejemplo, en Holguín al Oriente de la isla, el costo de los terrenos era bastante asequible. En barrios de ese término municipal la caballería de tierra se cotizaba a $\$ 75,00$ en Alcalá; $\$ 100,00$ en El Güiral y a \$150,00 en Tacajó y Bijarú. En ese caso, con una suma de mil pesos, obtenida como pago de haberes, se podían adquirir 13.3 caballerías en Alcalá, en El Güiral 10 caballerías y en Tacajó y Bijarú 6.6 caballerías. ${ }^{21}$ Una cantidad considerable de tierra para convertirse en terratenientes e invertir en un negocio que le demandaría resultados por largo tiempo.

La paga de los haberes recibidas por los líderes militares, sobre todo los altos oficiales, y los dividendos obtenidos en sus nuevos negocios, tanto en zonas urbanas como rurales, les permitió reorientar sus funciones hacia la explotación de colonias de caña, fincas de ganado o tabaco. De este arraigo local y regional de la antigua jefatura militar y política de la revolución, la mayoría procedente de familias de solvencia y prestigio, favorable en la definición de las estructuras de relaciones sociales de clientelas, emergerían los caciques políticos.

${ }^{21}$ La caballería era una medida de superficie utilizada por los españoles y sus colonias. En Cuba la caballería de tierra equivalía a $134202,38 \mathrm{~m}^{2}$. 


\section{Conclusiones}

El pago al Ejército cubano fue prioridad para la República de Cuba desde su fundación en 1902. Los pagos de guerra, además de convertirse en un sinónimo de enriquecimiento, se tradujeron en una ganancia a escala política. La mayor parte de los cargos públicos fueron ocupados por libertadores cubanos que bajo el clientelismo político, el intercambio de favores, la compra de votos y la relación con las empresas extranjeras, les posibilitó a los gobiernos locales y nacionales ejercer influencia en la sociedad, dado por la credibilidad en la gestión de un antiguo veterano de la guerra cubana.

En el afán por insertarse en la nueva sociedad republicana, donde la burguesía tendría los mayores beneficios y el papel preponderante, los altos oficiales del Ejército Libertador se alzaron como los nuevos inversores de la economía cubana, así como los nuevos políticos de la República desarrollando el fenómeno político en Cuba conocido como caciquismo.

El antes mencionado estudio de caso demostraría la existencia del caciquismo político en la región de Holguín. Se pudo constatar que, de los individuos analizados, todos ex miembros del Ejército cubano, la inmensa mayoría alternaría su profesión con una actividad política; dígase médico-Concejal, abogado-Alcalde, etc. Es decir, la actividad política con la actividad económica, dígase terrateniente-representantes a la Cámara, colonos, alcaldes, etc.

Metodológicamente, esta investigación sería imposible realizarla sin un detallado trabajo con las fuentes primarias constituyendo los Archivos provinciales los que atesoran la mayor riqueza en información. El Archivo Provincial de Holguín agrupa en sus fondos las listas de pago al Segundo Cuerpo del Ejército y a su vez posee la mayor cantidad de documentación resguardada del norte del oriente cubano. Por su parte, el Archivo Nacional de Cuba posee las actas de los Ayuntamientos del país donde se puede leer en sus sesiones la actividad de los caciques.

El caciquismo como fenómeno generalizado en todo el país asumió rasgos similares al del resto de América Latina, aunque de manera tardía debido a la fecha de eclosión del proceso independentista cubano. No obstante, la dinámica de guerra irregular, en un contexto libertador donde la región y la localidad les imprimieron un sello característico a las acciones militares, favoreció el desarrollo y arraigo de los líderes en las respectivas comarcas, con las consecuentes articulaciones de las redes clientelares que se activarían con finalidades políticas en los escenarios posbélicos.

El pago de los haberes de guerra al Ejército cubano fue el elemento que viabilizó el tránsito del caudillo militar al cacique político. El dinero no solo le permitió al ex oficial libertador su remuneración por haber luchado en la guerra, sino le facilitó su ascenso social a través de la adquisición de propiedades y/o puestos públicos. 


\section{Fuentes consultadas}

\section{Fuentes primarias}

ARCHIVO MUSEO PROVINCIAL DE HISTORIA DE HOLGUIN, (AMPHH), Holguín, Cuba

Fondo José A. García Castañeda

ARCHIVO NACIONAL DE CUBA, La Habana, Cuba (ANC)

Fondos Donativos y Remisiones; Gobierno de la Revolución del 95; Secretaría de Gobernación

\section{Fuentes bibliográficas}

IBARRA CUESTA, Jorge: Cuba 1898-1921 ..., La Habana, Editorial de Ciencias Sociales, 1992.

IBARRA CUESTA, Jorge: Cuba: 1899-1920. Partidos politicos y clases sociales, La Habana, Editorial Ciencias Sociales, 1992, p. 194.

IBARRA CUESTA, Jorge: Patria, etnia y nación, La Habana, Editorial Ciencias Sociales, 2007, p. 172.

LÓPEZ MIR, Elizabeth: El caciquismo politico en la región histórica de Holguin (1899-1920), Tesis de Maestría, La Habana, Instituto de Historia de Cuba, 2016.

MARIAL, Iglesias: Las metáforas del cambio en la vida cotidiana: Cuba 1898-1902, La Habana, Ediciones Unión, 2010, p. 23.

PICHARDO, Hortensia: Documentos para la historia de Cuba Tomo II, La Habana, Editorial Ciencias Sociales, 1973, p. 30.

RODRÍGUEZ, Rolando: "La disolución de Ejército Libertador. El gran objetivo de los Estados Unidos", Temas, No. 12-13, 1998, p. 43.

ROLOFF, Carlos: Índice alfabético y defunciones del Ejército Libertador de Cuba, La Habana, Rambla y Bouza, 1901. 